\title{
Postpartum behaviour as predictor of weight change from before pregnancy to one year postpartum
}

\author{
Ellen Althuizen ${ }^{1}$, Mireille NM van Poppel ${ }^{1 *}$, Jeanne $\mathrm{H}$ de Vries $^{2}$, Jacob C Seidell ${ }^{3}$, Willem van Mechelen ${ }^{1}$
}

\begin{abstract}
Background: Postpartum weight retention affects many women and increases the risk of becoming overweight. The research objective was to study modifiable factors contributing to weight change at one year postpartum.

Methods: In this prospective cohort, postpartum behavior, such as physical activity, sedentary behavior, sleep, and intake of total energy, total fat and saturated fatty acids of 118 Dutch women were assessed in 2003/2004 by selfreport at 6 weeks, 6 and 12 months postpartum. Mean postpartum scores were computed for the behavioral measures. In linear regression models it was determined which factors were associated with average weight change from before pregnancy to one year postpartum. Furthermore, factors associated with substantial postpartum weight retention ( $\geq 5 \mathrm{~kg}$ ) were also studied in logistic regression models.

Results: At one year postpartum, the average weight of participants had increased by $0.9 \mathrm{~kg}$ (SD 4.4). Moreover, $20 \%$ of the women retained $\geq 5 \mathrm{~kg}$. Women who perceived themselves more physically active than others were almost ten times less likely to retain $\geq 5 \mathrm{~kg}$ than women who perceived themselves equally active $(\mathrm{OR}=0.11,95 \%$ $\mathrm{Cl}: 0.02-0.66)$. Exceeding the guideline for saturated fatty acid intake $(\mathrm{OR}=3.40,95 \% \mathrm{Cl}: 1.04-11.11)$, total gestational weight gain $(\mathrm{OR}=1.14 / \mathrm{kg}, 95 \% \mathrm{Cl}: 1.01-1.27)$, and not having completed post high school education $(\mathrm{OR}=5.13,95 \% \mathrm{Cl}: 1.66-15.90)$ increased the odds of retaining $\geq 5 \mathrm{~kg}$.

Conclusions: Since one in five women had substantial weight retention postpartum, effective interventions for the prevention of weight retention are much needed. Future studies should evaluate whether interventions focusing on the identified modifiable postpartum factors are successful in reducing weight retention after childbirth.
\end{abstract}

\section{Background}

The period after giving birth represents an important window for overweight prevention [1-3]. From conception to one year after giving birth, women are reported to gain between 0.5 and $3.0 \mathrm{~kg}$ on average [4-7]. Twelve to $25 \%$ of women cope with a substantial weight retention of $5 \mathrm{~kg}$ or more postpartum [4,7]. Weight retained after giving birth appears to be deposited in body fat centrally rather than peripherally $[7,8]$. Since overweight and a less favorable distribution of body fat are known risk factors for morbidity and mortality, it is important to study weight retention after women have given birth.

\footnotetext{
* Correspondence: mnm.vanpoppel@vumc.nl

'van der Boechorststraat 7, 1081 BT Amsterdam, The Netherlands

Full list of author information is available at the end of the article
}

Gestational weight gain is the most consistently reported predictor of postpartum weight retention $[5-7,9,10]$. Other identified risk factors include nonwhite race, low socioeconomic status, and primiparity [11-13]. Only three studies reported on a multivariable approach including a variety of postpartum behavioral factors. Olson et al concluded that women who exercised "often" and those who perceived their energy intake to be decreased six to12 months postpartum had lower odds of retaining substantial weight [14]. Oken and colleagues concluded that hours of television viewing and trans fat intake increased the risk of substantial weight retention, whereas walking was a significant preventative factor [15]. Gunderson concluded that women sleeping $\leq 5$ hours per day at six months postpartum had a threefold higher risk of substantial weight retention at one year postpartum [16].

\section{C) Biomed Central}


Altogether, multivariable studies indicate that postpartum behaviour is of importance with regard to postpartum weight change. Such studies are very limited, however, and the need remains to improve our insight, being critical for the design of future intervention programmes [17]. Therefore, in addition to gestational weight gain and demographic variables, a number of postpartum behaviours such as physical activity, sedentary behaviour, sleep, and dietary intake were considered in the present paper, supplemented with data on meeting physical activity and dietary intake guidelines. These factors were chosen based on the previously mentioned studies, and from studies examining predictors of weight gain in general. The objective of the present study was to specify the relative importance of these repeatedly assessed postpartum behaviours with regard to both absolute and substantial (at least five kilograms) weight change at one year postpartum. The cut off point of five kilograms was chosen as a measure for identifying women who experience significant weight shifts after pregnancy $[16,18]$.

\section{Methods}

\section{Study design}

This paper focuses on the longitudinal analysis of data reported at 30 weeks pregnancy and 6 weeks, 6 and 12 months postpartum. The data collection was conducted via mailed questionnaires from June 2003 to November 2004. Written informed consent was obtained from every respondent. The Medical Ethics Committee of the VU (Vrije Universiteit) University Medical Center, Amsterdam, the Netherlands approved the study protocol.

\section{Study sample}

The Municipal Health Services of Amsterdam, which has a registry of almost all pregnant women in Amsterdam and the surrounding area, because they are responsible for blood screening in pregnancy, cooperated in the recruitment phase. First, 550 women of eighteen years or more were randomly selected by the Municipal Health Services to be invited to participate in our study. No upper age limit was used. We were allowed to send one mailed invitation, accompanied with some demographic questions, and one reminder invitation. There was no telephone contact during the recruitment phase for privacy reasons. Written informed consent was obtained from every respondent. After having given consent, reminder phone calls were made for follow-up questionnaires.

\section{Outcome measures}

Two outcome measures were defined in order to study weight change 12 months after giving birth:

(1) total postpartum weight change $(\mathrm{kg})$ as a continuous variable. This outcome measure was defined as the difference between postpartum weight (reported at 12 months postpartum) and prepregnancy weight (reported at 30 weeks pregnancy);

(2) substantial postpartum weight retention was defined as a weight retention $\geq 5 \mathrm{~kg}$ at 12 months postpartum, as a dichotomous variable $(\mathrm{y} / \mathrm{n})$.

\section{Behavioral covariates}

Covariates were repeatedly assessed at 6 weeks, 6 and 12 months postpartum and mean postpartum scores of these measures were computed.

Physical activity (PA) was assessed by means of the SQUASH (the Short QUestionnaire to Assess Healthenhancing physical activity) a reliable and reasonably valid questionnaire, that can be used to rank adults according to their PA levels [19]. Minutes per day and number of days per week spent on activities were assessed in four domains: commuting, work, household work, and leisure time activities. Initially, the mean number of minutes spent per day in the first year postpartum on light PA ( $<4$ Metabolic Equivalents, METs) and on moderate or vigorous PA ( $\geq 4$ METs) were derived from the questionnaire. Second whether or not participants met the Dutch PA guideline [20], i.e. accumulating at least 30 minutes of moderate or vigorous physical activity on at least five days per week, was determined. The PA guideline was not deemed applicable six weeks after childbirth, since women are often recommended not resume their normal PA program before that time. The mean postpartum score for meeting the PA guideline was categorized as never/sometimes/always meeting the guideline at the three moments of measurement.

We also determined social comparison for PA to gain insight into how respondents perceived their individual PA level, comparing themselves with other women in the first year postpartum. At each measurement, women responded to the statement: "I think I am a lot less/a little less/equally/a little more/a lot more physically active than other women". The outer categories on both ends were combined with their neighboring category because they were hardly used. The resulting three categories (a little or a lot less/equally/a little or a lot more) were used in the analyses.

Time spent sleeping and time spent sitting and resting (lying down but not sleeping) were assessed. The following questions were used: "In the last week, how many hours did you sit/rest/sleep during a 24-hour day?" This was requested for week and weekend days separately, to reduce reporting bias owing to divergent activities on week and weekend days that are usual for working people. Finally, mean values over the three postpartum time points were computed for total hours per week spent on these behaviors. 
The Dutch food frequency questionnaire was developed at the Division of Human Nutrition of the Wageningen University and validated to assess the intake of total energy, total fat and different types of fatty acids $[21,22]$. The original FFQ has been updated twice based on data of Dutch national food consumption surveys in 1992 and 1998 [23,24]. It is a 104-item questionnaire in which the women reported their food consumption of the previous four weeks. Frequency of foods used, as well as preparation methods, portion sizes and additions can be filled out. Using the Dutch food composition table of 2001 [25], the following measures were derived from this questionnaire: (1) total energy intake ( $\mathrm{kJ} /$ day), (2) percentage of total energy intake derived from fat intake, and (3) percentage of total energy intake derived from saturated fatty acid intake. Furthermore, we determined whether or not participants met the guidelines of the Dutch Health Council for total fat intake $(<40 \%$ of total energy intake) and for saturated fatty acid intake ( $<10 \%$ of total energy intake) [26]. Subsequently, mean scores of the three postpartum measurements were computed, illustrating whether participants always, sometimes or never met the guideline. Because the majority $(75 \%)$ of participants always met the fat intake guideline, the "never" group (3\%) was combined with the "sometimes" group (22\%) in the analyses. With regard to saturated fatty acid intake, $37 \%$ never met the guideline, and the "sometimes" group (53\%) was combined with the "always" group (9\%).

Finally, in each questionnaire participants were asked to report on their breastfeeding practices. This variable was categorized into the following tertiles: never/up to four months/longer than four months. The cut point of four months postpartum was chosen since this time point is the time many women stop breastfeeding in the Netherlands.

\section{Demographics and other covariates}

Total gestational weight gain was calculated by subtracting prepregnancy weight (reported at 30 weeks gestation) from end of pregnancy weight (reported at 6 weeks postpartum). Ethnicity was derived from the participant's parents' country of birth. An individual was considered to be European (which is in most cases Caucasian) when both parents were born in Europe. Further, educational level was operationalised as the highest level of education an individual reported to have completed. In this study, educational level was dichotomized into whether or not women had completed post high school education. Finally, participants were asked to report on their employment status $(y / n)$, smoking status $(y / n)$, family status (single or living alone/married or living together), and their health (excellent/very good/good/ moderate/bad) [27].

\section{Statistical analyses}

The analyses were conducted with SPSS 12.0.2. Dummy variables of categorical variables were generated and included in the regression models. Univariate predictors were selected $(\mathrm{p}<0.2)$ for both outcomes separately. Two multiple regression models were developed by means of the stepwise forward method, with a significance level of $\mathrm{p}<0.05$ : (1) a linear model with the dependent measure total postpartum weight change, and (2) a logistic model with the dependent measure substantial postpartum weight retention of $5 \mathrm{~kg}$ or more. All analyses were adjusted for prepregnancy body mass index (BMI). Finally, as a measure of model fit, the adjusted $\mathrm{R}$-square was determined for the linear model.

\section{Results}

Initially, 168/550 (31\%) women returned the first questionnaire. Subsequently, exclusions were made based on a preterm delivery at fewer than 36 weeks gestation $(\mathrm{n}=$ 3 ), when one or more questionnaires from 6 weeks, 6 or 12 months postpartum were not returned $(n=45)$, or when a subsequent pregnancy was reported within 12 months postpartum $(n=2)$, leaving a sample of 118 women for the analysis. Characteristics of our final study sample of 118 women are shown in Table 1. Most women (86\%) were employed, and $97 \%$ were married or living with a partner. Almost half of the women (49\%) were nulliparous, $40 \%$ primiparous, and $11 \%$ multiparous. Compared with the general population of Dutch pregnant women, our study sample had a comparable age and distribution of parity [28]. In our sample, 93\% was European, which is considerably more than the $84 \%$ in the general population [28]. The women had a mean total gestation of 39.7 (SD 1.4) weeks. The last time they weighed themselves during pregnancy was at 39.2 (SD 1.5) weeks gestation on average. Mean total gestational weight gain was 14.4 (SD 4.9) kg (Figure 1), and ranged from 3.0 to $23.0 \mathrm{~kg}$. In Table 2, data on

\section{Table 1 Population characteristics $(\mathrm{N}=118)$}

\begin{tabular}{ll}
\hline & mean (SD) \\
\hline Age, y & $31.6(4.3)$ \\
Age at menarche, y & $13.2(1.5)$ \\
Pre-pregnancy BMI, $\mathrm{kg} / \mathrm{m}^{2}$ & $24.3(3.7)$ \\
\hline & $\%(\mathbf{n})$ \\
\hline Pre-pregnancy BMl group & \\
Underweight (BMI < 18.5) & $11(8)$ \\
Normal weight (BMl 18.5 - 24.9) & $52(61)$ \\
Overweight (BMI 25 - 29.9) & $30(36)$ \\
Obese (BMI $\geq 30)$ & $7(8)$ \\
Educational level & $32(38)$ \\
Not completed post high school education & $68(80)$ \\
Completed post high school education &
\end{tabular}




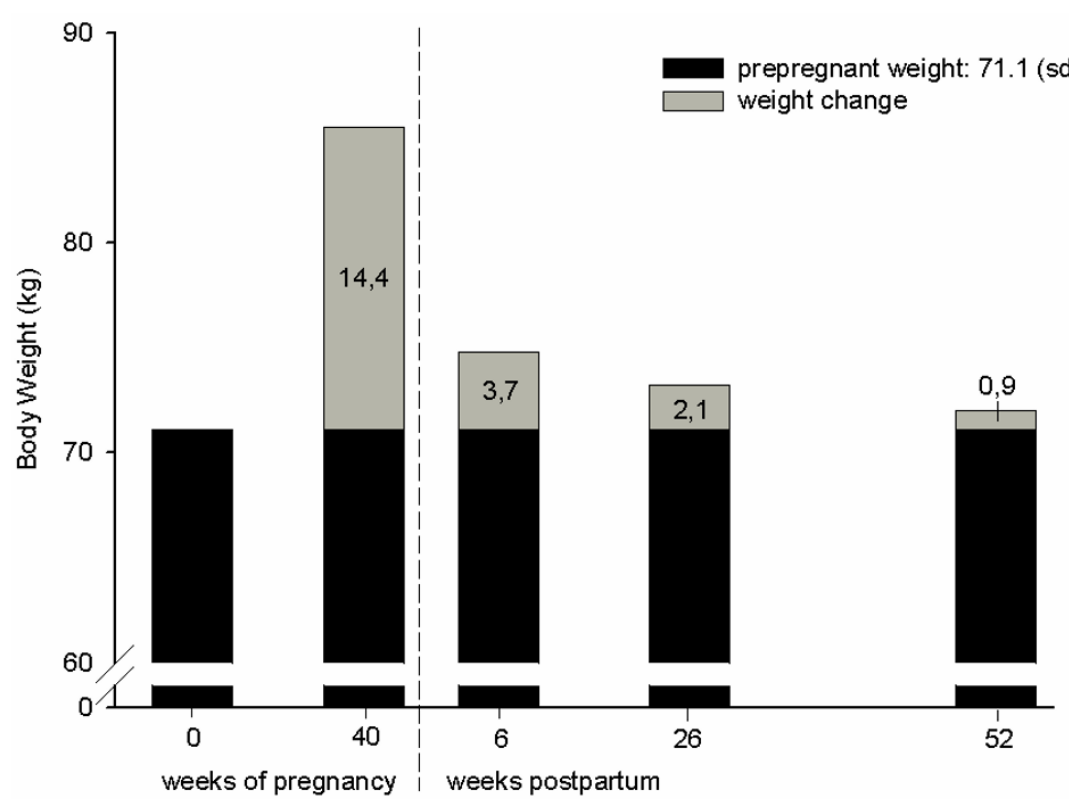

Figure 1 Mean body weight $(\mathrm{kg})$ before pregnancy, and mean weight change $(\mathrm{kg})$ during and after pregnancy $(\mathrm{n}=118)$.

self-reported lifestyle behaviour at 6 weeks, 6 and 12 months postpartum are presented. In this first year postpartum $10 \%$ of the women reported that they smoked.

\section{Absolute postpartum weight change}

Postpartum weight change decreased from $3.7 \mathrm{~kg}$ (SD 4.2) at 6 weeks postpartum, to $2.1 \mathrm{~kg}(\mathrm{SD} 4.3)$ at 6 months postpartum, to $0.9 \mathrm{~kg}(\mathrm{SD} 4.4)$ at 12 months postpartum (Figure 1). Absolute weight change at 12 months postpartum varied between -10.0 and $+11.0 \mathrm{~kg}$, and was normally distributed.

In Table 3, the results of linear regression models are presented with absolute weight change at 12 months postpartum as the dependent variable. The final model ( $\mathrm{p}<0.01$ ) explained $13 \%$ of the variance in absolute weight change. Women who perceived themselves to be more physically active than other women had significantly less weight retention. Also, women with a below average total energy intake had less weight retention compared with women with an average total energy intake. Sleeping showed an inverse association with absolute weight change, meaning that women who slept more retained less weight. Total gestational weight gain was significantly associated with absolute weight change.

\section{Substantial postpartum weight retention}

In this study sample, $20 \%(23 / 118)$ of the women retained a substantial amount of weight of $\geq 5 \mathrm{~kg}$ at 12 months postpartum. The results of the final logistic regression model are shown in Table 3 . Women who perceived themselves to be more physically active than others had an almost ten times lower odds of retaining a substantial amount of weight. Women who always exceeded the guideline of saturated fatty acid intake had a more than threefold higher odds compared with others. In addition, higher gestational weight gain increased the odds of retaining $\geq 5 \mathrm{~kg}$. Finally, women who had not completed post high school education were more than five times as likely to retain substantial weight compared with women who did complete post high school education.

Meeting the guidelines for PA or fat intake did not significantly add to the final models of absolute or substantial postpartum weight retention. The same was true for the continuous measures of PA, for sitting, breastfeeding, and smoking behaviour, and for sociodemographic variables like ethnicity and parity. Prepregnancy BMI was not related to weight retention postpartum in either of these models.

\section{Discussion}

Since studies that longitudinally looked at the influence of multiple postpartum behaviors on postpartum weight changes are scarce, we conducted a study in which the association of factors such as postpartum physical activity, sedentary behavior, sleep, and dietary intake with postpartum weight change were assessed. In our study, perceived physical activity, total energy intake, postpartum sleep, total gestational weight gain, and educational level were independently associated with weight change from before pregnancy to 12 months postpartum. These results 
Table 2 Self-reported lifestyle behaviour in the first year postpartum

\begin{tabular}{|c|c|}
\hline Lifestyle behaviour & $n=118$ \\
\hline Light physical activity, min/d, median (10-90 th $\%)$ & $323(191-472)$ \\
\hline $\begin{array}{l}\text { Moderate and vigorous physical activity, } \mathrm{min} / \mathrm{d} \text {, } \\
\text { median }\left(10-90^{\text {th }} \%\right)\end{array}$ & $31(10-93)$ \\
\hline \multicolumn{2}{|l|}{ Participants meeting physical activity guideline, \% (n) } \\
\hline Never (not at 6 and 12 months pp) & $40(47)$ \\
\hline Sometimes (only at 6 or 12 months pp) & $33(39)$ \\
\hline Always (at 6 and 12 months pp) & $27(32)$ \\
\hline \multicolumn{2}{|l|}{ Social comparison for physical activity, \% (n) } \\
\hline Less active than others & $27(32)$ \\
\hline Equally active as others & $36(43)$ \\
\hline More active than others & $36(43)$ \\
\hline Sitting, hours/day, mean (SD) & $6.5(2.7)$ \\
\hline Resting, hours/day, mean (SD) & $1.2(1.2)$ \\
\hline Sleeping, hours/day, mean (SD) & $7.8(1.3)$ \\
\hline \multicolumn{2}{|l|}{ Total energy intake, tertiles, $\%(n)$} \\
\hline Below average $(<628 \mathrm{~kJ} /$ day $)$ & $33(39)$ \\
\hline Average (628 to $803 \mathrm{~kJ} /$ day) & $34(40)$ \\
\hline Above average (> $803 \mathrm{~kJ} /$ day) & $33(39)$ \\
\hline $\begin{array}{l}\text { Fat intake as percentage of total energy intake, mean } \\
\text { (SD) }\end{array}$ & $32.6(5.0)$ \\
\hline Participants always meeting fat intake guideline, \% (n) & $75(98)$ \\
\hline $\begin{array}{l}\text { Saturated fatty acid intake as percentage of total } \\
\text { energy intake, mean (SD) }\end{array}$ & $11.5(2.6)$ \\
\hline $\begin{array}{l}\text { Participants always/sometimes meeting saturated fatty } \\
\text { acid guideline, } \%(n)\end{array}$ & $63(74)$ \\
\hline \multicolumn{2}{|l|}{ Breastfeeding, \% (n) } \\
\hline Never & $26(31)$ \\
\hline Up to 4 months & $42(49)$ \\
\hline Longer than 4 months & $32(38)$ \\
\hline
\end{tabular}

Scores at 6 weeks, 6 and 12 months postpartum were computed into mean postpartum values.

indicate that total pregnancy weight gain combined with postpartum behaviours influence the degree of weight change following pregnancy.

A general comment should be made with regard to postpartum weight change. Studies on weigh retention generally reported weight changes of 0.5 to $3.0 \mathrm{~kg}$ [4-7,15,29,30], while they examined a period of more than one year. The total population, however, will also gain weight over the same time period [31]. Our participants retained on average $0.9 \mathrm{~kg}$ in about 18 months, which was similar to weight gain in a cohort of Dutch non-pregnant women of a comparable age, who gained $0.6 \mathrm{~kg}$ per year [31]. Of course these data originated from different samples, but they certainly illustrate that in a Dutch population weight change attributed to pregnancy may be less profound than in other populations.

Whatever the amount of weight gain caused by pregnancy, the fact remains that a substantial proportion of women are much heavier 12 months postpartum than they were before pregnancy. In our study $20 \%$ of women retained $5 \mathrm{~kg}$ or more. This is quite similar to other recent studies, conducted in the US or Europe, that found that between 13 and $20 \%$ gained $5 \mathrm{~kg}$ or more at 12 months postpartum $[7,14,29,32]$.

\section{Behavioral predictors of postpartum weight change}

Participants in the present study who perceived themselves to be more physically active than others were less likely to retain substantial weight after pregnancy, underlining conclusions of earlier studies which reported on beneficial associations between postpartum PA and body weight $[15,30,33]$. In contrast, the more in-depth measures derived from our activity questionnaire were not associated. There was only a moderate correlation between "social comparison for PA" and minutes spent in "at least moderate PA" derived from the SQUASH $(\mathrm{r}=$ $0.41, \mathrm{p}=0.00$; data not shown), which indicates that the brief item is likely to reflect a different concept of PA behaviour.

In the present study, an association between total energy intake and weight retention was found. Previous studies also found that relatively high levels of energy intake were linked to increased (risk of substantial) postpartum weight change [14,15,33-35]. However, not only total energy intake may be important, also food quality (i.e. specific nutrients) may play a role in weight change, and advice about intake of specific nutrients might be more effective than advice about total energy intake $[26,36]$. Thus far, only Oken and colleagues investigated measures of food intake in the postpartum period [15]. They concluded that trans fat intake was a predictor of substantial postpartum weight gain. In addition to this finding, the present study shows that high intakes of saturated fatty acids in the first year postpartum are associated with a higher risk of substantial weight retention. Given the scarcity of studies, the relationship between postpartum weight retention and other qualitative measures of food intake, e.g. fibre intake, deserves further research.

Sedentary behaviour in the postpartum period was only studied before by Oken and colleagues, who demonstrated that women who watched fewer than two hours of television were about five times less likely to retain $\geq 5 \mathrm{~kg}$ [15]. In our study, evidence for a relationship with sitting or resting time was absent, perhaps because we did not ask for a specific behaviour such as television watching, but the total time of sitting per day, which is possibly more difficult to estimate.

Interestingly, a higher mean score of sleep in the first year postpartum was a significant protective factor for absolute weight change 12 months postpartum. Gunderson et al also found a protective effect of sleep for weight retention in the postpartum period [16]. It is hypothesised that women who sleep less because of long hours 
Table 3 Multivariable correlates of average weight change and substantial ( $\geq 5 \mathrm{~kg}$ ) weight retention at one year $\mathrm{pp}(\mathrm{n}=\mathbf{1 1 8})$

\begin{tabular}{|c|c|c|}
\hline Absolute weight change $(\mathrm{kg})$ & B & $95 \% \mathrm{Cl}$ \\
\hline \multicolumn{3}{|l|}{ Social comparison for physical activity } \\
\hline equally active (ref) & 0 & \\
\hline less active & 0.57 & $-1.35-2.49$ \\
\hline more active & $-2.43^{* *}$ & $-4.53--0.71$ \\
\hline Sleep (h/day) & $-0.53^{*}$ & $-1.08--0.02$ \\
\hline \multicolumn{3}{|l|}{ Energy intake ${ }^{b}$} \\
\hline average (ref) & 0 & \\
\hline below average & $-2.62^{* *}$ & $-3.73--0.16$ \\
\hline above average & -1.47 & $-3.35-0.42$ \\
\hline Total gestational weight gain $(\mathrm{kg})$ & $0.18^{*}$ & $0.01-0.34$ \\
\hline Substantial weight retention ( $\geq 5 \mathrm{~kg}$ ) & OR & $95 \% \mathrm{Cl}$ \\
\hline \multicolumn{3}{|l|}{ Social comparison for physical activity } \\
\hline equally active & 1 & \\
\hline less active & 1.90 & $0.59-6.08$ \\
\hline more active & $0.11^{*}$ & $0.02-0.66$ \\
\hline \multicolumn{3}{|l|}{ Meeting saturated fatty acid intake guideline } \\
\hline Yes & 1 & \\
\hline No, exceeding guideline & $3.40^{*}$ & $1.04-11.11$ \\
\hline Total gestational weight gain $(\mathrm{kg})$ & $1.14^{*}$ & $1.01-1.27$ \\
\hline \multicolumn{3}{|l|}{ Education } \\
\hline Completed post high school education & 1 & \\
\hline Not completed post high school education & $5.13^{* *}$ & $1.66-15.90$ \\
\hline
\end{tabular}

All models were adjusted for prepregnancy BMI.

* for $p<0.05$, and ${ }^{* *}$ for $p<0.01$.

caring for their babies [37] may be especially susceptible to weight gain, or not able to lose weight postpartum. Further assessment of the relation between postpartum weight retention and (determinants of) sleep in the postpartum period is, however, warranted.

Breastfeeding status was no significant predictor in either of the presented models. Breastfeeding in relation to postpartum weight changes has been studied frequently, but the evidence is inconclusive; ranging from negative to weak positive associations, or not a significant association at all [14,37-39].

\section{Limitations and strengths}

Several limitations should be taken into account when our results are interpreted. The low response rate is the main drawback of this study. The resulting relatively small sample size undermines the discriminating power of the presented data, which may partially account for the limited explained variance of the linear regression model (13\%). In addition, the overrepresentation of European and welleducated participants undermines the generalisability of our findings. The foremost objective of the current study was to describe the strength and direction of significantly associated factors of postpartum weight change, which was not undermined by this selectivity. Another limitation was that self-reported measures were used, where objective, more precise measures would have been preferred. Furthermore, some of the instruments were not validated, and none were validated in pregnant or postpartum women. Body weight, energy intake and physical activity are especially known to be subject to reporting bias with increasing overweight $[41,42]$. It was not possible to confirm the data objectively owing to practical limitations (e.g. assessing body weight is not common practice in Dutch midwifery). Still, since both outcome variables were based on change scores, and assuming that underreporting of body weight is rather consistent over time, reporting bias might not have affected the outcome measures as such. Lastly, we combined data from all three time points postpartum into one score for average postpartum behaviour. This strategy did not allow looking at the importance of early or late postpartum behaviour for postpartum changes in weight.

The foremost strength of our study is its prospective design. Repeatedly assessed measures, which were computed into mean postpartum scores in the first year postpartum, decreased standard errors of the correlates that were studied. Besides this, finding comparable results in both regression models can be seen as confirmation that the reported predictors are indeed of value with regard to postpartum weight change. Last but not least, reporting on multivariate associations, hereby controlling for co-linearity (which is common between behaviours - especially with regard to PA and energy intake), enabled us to draw conclusions about the relative importance of the assessed measures.

\section{Conclusions}

Postpartum lifestyle factors such as PA, sleep, energy intake, and meeting the guideline for saturated fatty acid intake, total gestational weight gain and educational level were identified as factors related to postpartum weight change. Future interventions should evaluate whether guidance with regard to the identified modifiable postpartum factors may be able to reduce weight retention after childbirth, hereby improving maternal health.

\section{Acknowledgements}

This study was financially supported by a grant from The Netherlands Organization for Health Research and Development (ZonMw, grant 4010.0017).

\section{Author details}

'van der Boechorststraat 7, 1081 BT Amsterdam, The Netherlands. ${ }^{2}$ Department of Human Nutrition, Wageningen University, Wageningen, The Netherlands. ${ }^{3}$ De Boelelaan 1085, 1081 HV Amsterdam, The Netherlands.

\section{Authors' contributions}

MvP initiated and was PI of the study. MvP and EA designed the study. EA performed the 
statistical analysis assisted by MvP and JdV. EA wrote the manuscript. JdV, JS and WVM participated in the design of the study and contributed to the manuscript. All authors read and approved the final manuscript.

\section{Competing interests}

The authors declare that they have no competing interests.

Received: 31 August 2010 Accepted: 16 March 2011

Published: 16 March 2011

\section{References}

1. Gore SA, Brown DM, West DS: The role of postpartum weight retention in obesity among women: a review of the evidence. Ann Behav Med 2003, 26:149-159.

2. Sarwer DB, Allison KC, Gibbons LM, Markowitz JT, Nelson DB: Pregnancy and obesity: a review and agenda for future research. $J$ Womens Health 2006, 15:720-733.

3. Guelinckx I, Devlieger R, Beckers K, Vansant G: Maternal obesity: pregnancy complications, gestational weight gain and nutrition. Obes Rev 2008, 9:140-150

4. Keppel KG, Taffel SM: Pregnancy-related weight gain and retention: implications of the 1990 Institute of Medicine guidelines. Am J Public Health 1993, 83:1100-1103.

5. Linne Y, Barkeling B, Rossner S: Long-term weight development after pregnancy. Obes Rev 2002, 3:75-83.

6. Rooney BL, Schauberger CW: Excess pregnancy weight gain and longterm obesity: one decade later. Obstet Gynecol 2002, 100:245-252.

7. Gunderson EP, Murtaugh MA, Lewis CE, Quesenberry CP, West DS, Sidney S: Excess gains in weight and waist circumference associated with childbearing: The Coronary Artery Risk Development in Young Adults Study (CARDIA). Int J Obes Relat Metab Disord 2004, 28:525-535.

8. Smith DE, Lewis $C E$, Caveny $J$, Perkins LL, Burke GL, Bild DE: Longitudinal changes in adiposity associated with pregnancy. The CARDIA Study. Coronary Artery Risk Development in Young Adults Study. JAMA 1994, 8(271):1747-1751.

9. Gunderson EP, Abrams B: Epidemiology of gestational weight gain and body weight changes after pregnancy. Epidemiol Rev 2000, 22:261-274.

10. Kac G, Benicio MH, Velasquez-Melendez G, Valente JG, Struchiner CJ: Gestational weight gain and prepregnancy weight influence postpartum weight retention in a cohort of Brazilian women. J Nutr 2004, 134:661-666.

11. World Health Organization: In The challenge of obesity in the WHO European Region and the strategies for response Edited by: Branca F, Nikogosian $\mathrm{H}$, Lobstein T 2007.

12. Brownell KD: The central role of lifestyle change in long-term weight management. Clin Cornerstone 1999, 2:43-51.

13. Jebb SA: Dietary determinants of obesity. Obes Rev 2007, 8(Suppl 1):93-97.

14. Olson CM, Strawderman MS, Hinton PS, Pearson TA: Gestational weight gain and postpartum behaviors associated with weight change from early pregnancy to 1 y postpartum. Int I Obes Relat Metab Disord 2003, 27:117-127.

15. Oken E, Taveras EM, Popoola FA, Rich-Edwards JW, Gillman MW: Television, walking, and diet: associations with postpartum weight retention. Am J Prev Med 2007, 32:305-311.

16. Gunderson EP, Rifas-Shiman SL, Oken E, Rich-Edwards JW, Kleinman KP, Taveras EM, Gillman MW: Association of fewer hours of sleep at 6 months postpartum with substantial weight retention at 1 year postpartum. Am J Epidemiol 2008, 15(167):178-187.

17. Siega-Riz AM, Evenson KR, Dole N: Pregnancy-related weight gain-a link to obesity? Nutr Rev 2004, 62:S105-S111.

18. Schmitt NM, Nicholson WK, Schmitt J: The association of pregnancy and the development of obesity - results of a systematic review and metaanalysis on the natural history of postpartum weight retention. International Journal of Obesity 2007, 31:1642-1651.

19. Wendel-Vos GC, Schuit AJ, Saris WH, Kromhout D: Reproducibility and relative validity of the short questionnaire to assess health-enhancing physical activity. J Clin Epidemiol 2003, 56:1163-1169.

20. Hildebrandt VH, Ooijendijk WTM, Stiggelbout M: Trendrapport bewegen en gezondheid 1998/1999 Lelystad, NL: Koninklijke vermande; 1999, 23-29.
21. Feunekes GI, Van Staveren WA, De Vries JH, Burema J, Hautvast JG: Relative and biomarker-based validity of a food-frequency questionnaire estimating intake of fats and cholesterol. Am J Clin Nutr 1993, 58:489-496.

22. Feunekes IJ, Van Staveren WA, Graveland F, De Vos J, Burema J: Reproducibility of a semiquantitative food frequency questionnaire to assess the intake of fats and cholesterol in The Netherlands. Int $J$ Food Sci Nutr 1995, 46:117-123.

23. Netherlands Nutrition Centre: Zo eet Nederland 1992. (Dutch National Food Consumption Survey 1992) Netherlands Nutrition Centre, The Hague; 1993.

24. Netherlands Nutrition Centre: Zo eet Nederland 1998. (Dutch National Food Consumption Survey 1998) Netherlands Nutrition Centre, The Hague; 1998.

25. Netherlands Nutrition Centre: NEVO: Dutch food composition database 2001 Netherlands Nutrition Centre, The Hague; 2001.

26. Health Council of the Netherlands: Guidelines for a healthy diet 2006 The Hague: Health Council of the Netherlands, Publication no 2006/21; 2006

27. Nelson EC, Landgraf JM, Hays RD, Wasson JH, Kirk JW: The functional status of patients. How can it be measured in physician's offices? Med Care 1990, 29:1111-1126.

28. Stichting Perinatale Registratie Nederland: Perinatale zorg in Nederland 2003 Bilthoven: Stichting Perinatale Registratie Nederland; 2006.

29. Ohlin A, Rossner S: Maternal body weight development after pregnancy. Int J Obes 1990, 14:159-173.

30. Schauberger CW, Rooney BL, Brimer LM: Factors that influence weight loss in the puerperium. Obstet Gynecol 1992, 79:424-429.

31. Nooyens AC, Visscher TL, Verschuren WM, Schuit AJ, Boshuizen HC, van Mechelen W, Seidell JC: Age, period and cohort effects on body weight and body mass index in adults: The Doetinchem Cohort Study. Public Health Nutr 2008, 24:1-9.

32. Herring SJ, Rich-Edwards JW, Oken E, Rifas-Shiman SL, Kleinman KP, Gillman MW: Association of postpartum depression with weight retention 1 year after childbirth. Obesity 2008, 16:1296-1301.

33. Boardley DJ, Sargent RG, Coker AL, Hussey JR, Sharpe PA: The relationship between diet, activity, and other factors, and postpartum weight change by race. Obstet Gynecol 1995, 86:834-838.

34. Ohlin A, Rossner S: Trends in eating patterns, physical activity and sociodemographic factors in relation to postpartum body weight development. Br J Nutr 1994, 71:457-470.

35. Walker LO, Freeland-Graves JH, Milani T, George G, Hanss-Nuss H, Kim M, Sterling BS, Timmerman GM, Wilkinson S, Arheart KL, Stuifbergen A: Weight and behavioral and psychosocial factors among ethnically diverse, lowincome women after childbirth: II. Trends and correlates. Women Health 2004, 40:19-34.

36. US Health and Human Services and US Department of Agriculture, Dietary Guidelines for Americans 2005. 6 edition. Washington, DC: US Government Printing Office; 2005

37. Lee KA, Zaffke ME, McEnany G: Parity and sleep patterns during and after pregnancy. Obstet Gynecol 2000, 95:14-18.

38. Kac G, Benicio MH, Velasquez-Melendez G, Valente JG, Struchiner CJ: Breastfeeding and postpartum weight retention in a cohort of Brazilian women. Am J Clin Nutr 2004, 79:487-493.

39. Sichieri R, Field AE, Rich-Edwards J, Willett WC: Prospective assessment of exclusive breastfeeding in relation to weight change in women. Int $J$ Obes Relat Metab Disord 2003, 27:815-820.

40. Walker LO, Freeland-Graves J: Lifestyle factors related to postpartum weight gain and body image in bottle- and breastfeeding women. $J$ Obstet Gynecol Neonatal Nurs 1998, 27:151-160

41. Visscher TL, Viet AL, Kroesbergen IH, Seidell JC, et al: Underreporting of BMI in adults and its effect on obesity prevalence estimations in the period 1998 to 2001. Obesity 2006, 14:2054-2063.

42. Lichtman SW, Pisarska K, Berman ER, Pestone M, Dowling H, Offenbacher E, Weisel H, Heshka S, Matthews DE, Heymsfield SB: Discrepancy between self-reported and actual caloric intake and exercise in obese subjects. $N$ Engl J Med 1992, 327:1893-1898.

Pre-publication history

The pre-publication history for this paper can be accessed here: http://www.biomedcentral.com/1471-2458/11/165/prepub

doi:10.1186/1471-2458-11-165

Cite this article as: Althuizen et al:: Postpartum behaviour as predictor of weight change from before pregnancy to one year postpartum. BMC Public Health 2011 11:165. 